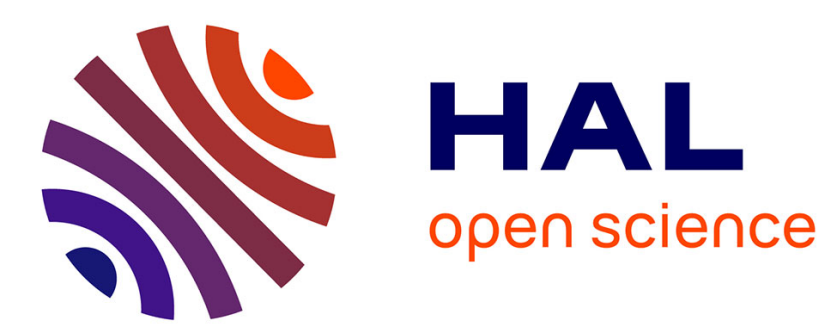

\title{
From Point Defects to Plate Tectonic Faults
}

Klaus Regenauer-Lieb, Bruce Hobbs, David Yuen, Alison Ord, Yanhua Zhang, Hans Bernd Muhlhaus, Gabriele Morra

\section{To cite this version:}

Klaus Regenauer-Lieb, Bruce Hobbs, David Yuen, Alison Ord, Yanhua Zhang, et al.. From Point Defects to Plate Tectonic Faults. Philosophical Magazine, 2007, 86 (21-22), pp.3373-3392. 10.1080/14786430500375159 . hal-00513626

\section{HAL Id: hal-00513626 \\ https://hal.science/hal-00513626}

Submitted on 1 Sep 2010

HAL is a multi-disciplinary open access archive for the deposit and dissemination of scientific research documents, whether they are published or not. The documents may come from teaching and research institutions in France or abroad, or from public or private research centers.
L'archive ouverte pluridisciplinaire HAL, est destinée au dépôt et à la diffusion de documents scientifiques de niveau recherche, publiés ou non, émanant des établissements d'enseignement et de recherche français ou étrangers, des laboratoires publics ou privés. 


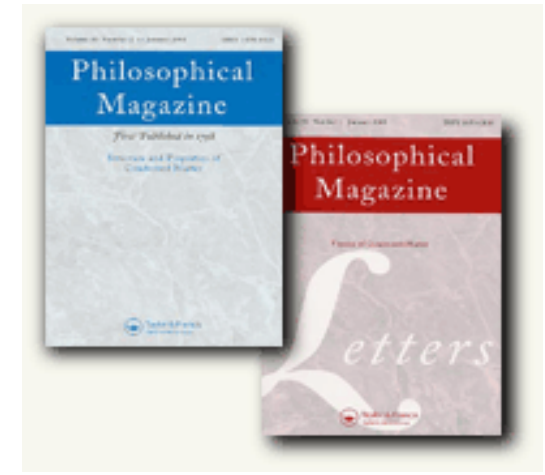

From Point Defects to Plate Tectonic Faults

\begin{tabular}{|r|l|}
\hline Journal: & Philosophical Magazine \& Philosophical Magazine Letters \\
\hline Manuscript ID: & TPHM-04-Dec-0112.R1 \\
\hline Journal Selection: & Philosophical Magazine \\
\hline Date Submitted by the & 30-Jun-2005 \\
\hline Complete List of Authors: & $\begin{array}{l}\text { Regenauer-Lieb, Klaus; Johannes Gutenberg University, } \\
\text { Geosciences; CSIRO, Exploration and Mining } \\
\text { Hobbs, Bruce; CSIRO, Exploration and Mining } \\
\text { Yuen, David; University of Minnesota, Department of Geology and } \\
\text { Geophysics and Supercomputer Institute } \\
\text { Ord, Alison; CSIRO, Exploration and Mining } \\
\text { Zhang, Yanhua; CSIRO, Exploration and Mining } \\
\text { Muhlhaus, Hans; University of Queensland, ESSCC } \\
\text { Morra, Gabriele; ETH, Geophysics }\end{array}$ \\
\hline Keywords: & $\begin{array}{l}\text { multiscale modelling, grain size, finite-element modelling, } \\
\text { dislocation mechanics, diffusion, deformation mechanisms, defects } \\
\text { in solids, crystal defects }\end{array}$ \\
\hline Keywords (user supplied): & \begin{tabular}{l} 
geodynamics \\
\hline
\end{tabular} \\
\hline
\end{tabular}

\section{(s) ScholaroNE \\ Manuscript Central}




\section{From Point Defects to Plate Tectonic Faults}

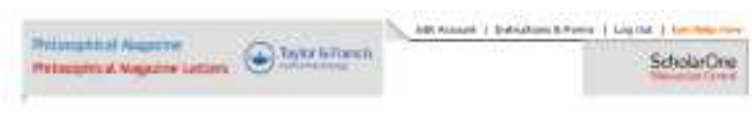

Manuscript ID: TPHM-04-Dec-0112.R1

Title: From Point Defects to Plate Tectonic Faults

Authors:

Regenauer-Lieb, Klaus; Johannes Gutenberg University, Geosciences; CSIRO, Exploration and

Mining

Hobbs, Bruce; CSIRO, Exploration and Mining

Yuen, Dave; University of Minnesota, Department of Geology and

Geophysics and

Supercomputer Institute

Ord, Alison; CSIRO, Exploration and Mining

Zhang, Yanhua; CSIRO, Exploration and Mining

Muhlhaus, Hans; University of Queensland, ESSCC

Morra, Gabriele; ETH, Geophysics

Date Submitted: 30-Jun-2005 


\title{
From Point Defects to Plate Tectonic Faults
}

\author{
Klaus Regenauer-Lieb ${ }^{1}$, Bruce Hobbs ${ }^{2}$, David A. Yuen ${ }^{3}$, Alison Ord ${ }^{2}$, Yanhua Zhang ${ }^{2}$, \\ Hans B. Mulhaus ${ }^{4}$ and Gabriele Morra ${ }^{5}$ \\ ${ }^{1}$ Johannes Gutenberg-Universität Mainz, Geophysics \& Geodynamics, 55099 Mainz, Germany, Phone \\ (++49)6131 3926594, ${ }^{2}$ CSIRO Exploration and Mining Perth (ARRC), PO Box 1130, Bentley WA 6102 , \\ Australia \\ ${ }^{3}$ Department of Geology and Geophysics and Supercomputer Institute \\ University of Minnesota Minneapolis, Minnesota 55455, USA \\ ${ }^{4}$ ESSCC, The University of Queensland, St Lucia, QLD 4072, Australia \\ ${ }^{5}$ ETH Zürich, Institute of Geophysics, 8093, Hönggerberg, Switzerland
}

Understanding and explaining emergent constitutive laws in the multi-scale evolution from point defects, dislocations and two-dimensional defects to plate tectonic scales is an arduous challenge in condensed matter physics. The Earth appears to be the only planet known to have developed stable plate tectonics as a means to get rid of its heat. The emergence of plate tectonics out of mantle convection appears to rely intrinsically on the capacity to form extremely weak faults in the top $100 \mathrm{~km}$ of the planet. These faults have a memory of at least several hundred millions of years, yet they appear to rely on the effects of water on line defects. This important phenomenon was first discovered in laboratory and dubbed "hydrolytic weakening". At the large scale it explains cycles of colocated resurgence of plate generation and consumption (the Wilson cycle), but the exact physics underlying the process itself and the enormous spanning of scales still remains unclear.

We present an attempt to use the multi-scale non-equilibrium thermodynamic energy evolution inside the deforming lithosphere to move phenomenological laws to laws derived from basic scaling quantities, develop self-consistent weakening laws at lithospheric scale and give a fully coupled deformation-weakening constitutive framework. At meso- to plate scale we encounter in a stepwise manner three basic domains governed by the diffusion/reaction time scales of grain growth, thermal diffusion and finally water mobility through point defects in the crystalline lattice. The latter process governs the planetary scale and controls the stability of its heat transfer mode. 


\section{Introduction}

It has long been argued that styles of planetary convection, emergence of plate tectonics and with it stable conditions for the evolution of life relies on just one vital ingredient: the stability of water within the outer planetary layer, its lithosphere and the convecting mantle [1]. While the difference of tectonic styles on Earth and Venus correlates with a lack of water in the Venerean atmosphere, its lithosphere and deeper mantle, conclusive proof for the underlying mechanism is still missing although some circumstantial evidence has been put forward [2-5]. The authors use the phenomenon of "hydrolytic weakening" observed and empirically quantified in laboratory experiments. They model its impact on faulting of the lithosphere or styles of convection within the mantle, however, the justification for scale invariance has not been investigated.

Is it justified to use laboratory creep laws obtained on samples of centimetre scale for thousands of kilometre scale simulations? Can processes that happen on the time scale of a single lattice vibration $\left(10^{-12} \mathrm{~s}\right)$ have an impact on the evolution of the Earth on the time scale of $\left(10^{16} \mathrm{~s}\right)$ ? Are laboratory experiments representative for plate tectonic extrapolations? In mining engineering it is for instance long known that rock strength is much higher when measured in the laboratory below $1 \mathrm{~m}^{3}$ scale than by load bearing jack measurements in the mine [6]. In the mine scale the elastic modulus appears to drop by almost an order of magnitude. Rock brittle processes, therefore show distinct scale dependence, i.e. they are not self-similar within the region of our observations. But is scale invariance guaranteed for creep laws in the thermally activated rock deformation regime if we consider only scales larger than the intrinsic ruler, the material length scale of plasticity. What are the material properties that govern the failure of the solid outer layer of the planet? We try to formulate an approach to answer these fundamental questions and also offer a method for tectonic scale classification introducing a diffusionreaction chart for faulting.

In the following we will first go through a micro- to meso-scale summary of the effect of water on the creep of the main mechanical constituent of the Earth's outer rigid layer, the mineral olivine, then we will discuss the basic length scales underlying plate tectonics. We go on to discuss a hierarchical mechanism (ductile feedback loop), which might potentially be responsible for an apparently fractal distribution of present plate sizes. Finally we will propose a first multi-scale framework capable of crossing the scales 
from point defects to plate tectonics. We do not discuss the influence water and chemical alteration on brittle seismogenic processes, a detailed review can be found elsewhere [7].

\section{Olivine $(\mathrm{Mg}, \mathrm{Fe})_{2} \mathrm{SiO}_{4}$}

The Earth's silicate mantle comprises $68 \%$ of the Earth's mass and is mostly made up of $\mathrm{Fe}, \mathrm{Mg}$ silicates. The Earth's mantle extends down to $2883 \mathrm{~km}$ depth and on $70 \%$ of the Earth surface it is covered by a thin veneer $(6-8 \mathrm{~km})$ of oceanic crust, which is also mostly composed of rocks with $\mathrm{Fe}, \mathrm{Mg}$ silicate composition. The remaining $30 \%$ of the Earth surface is more differentiated into light elements like $\mathrm{K}, \mathrm{Na}, \mathrm{Si}, \mathrm{Ca}, \mathrm{Al}$ silicates. The continental crust is about 30-80 km thick, and maximum under mountain ranges. Chemical stratification of the Earth from the original solar abundances into a core mantle - crust composite is mainly due to an early melting episode followed by a migration of siderophile elements into the core and a converse incorporation of lithophile elements into the mantle.

The main mechanical constituent in the Earth mantle is the mineral olivine which has an orthorombic symmetry and a continuous transition from Forsterite $\left(\mathrm{Mg}_{2} \mathrm{SiO}_{4}\right)$ to Fayalite $\left(\mathrm{Fe}_{2} \mathrm{SiO}_{4}\right)$ with high $\mathrm{p}, \mathrm{T}$ polymorphs olivine $(\alpha)$, spinel $(\beta, \gamma)[8]$.

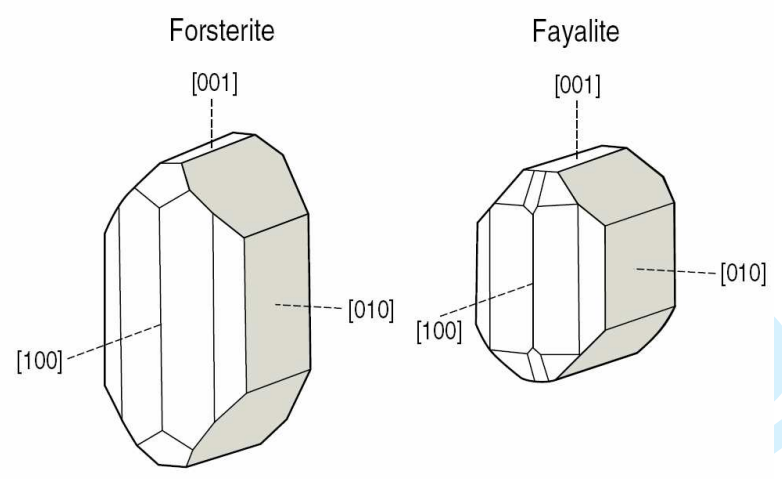

Figure 1 The olivine group mineral Forsterite $\mathrm{Mg}_{2} \mathrm{SiO}_{4}$ (left) and Fayalite $\mathrm{Fe}_{2} \mathrm{SiO}_{4}$ (right) provide the main mechanical constituent in the Earth's mantle. They have an orthorhombic symmetry. 
Figure 2 Series of polarized spectra indicate diffusion of water into a synthetic iron free dry forsterite sample $2.5 \times 3 \times 2 \mathrm{~mm}^{3}$. Water is supplied in a step function through hydrothermal annealing fitted by a complementary error function diffusion profile. OH-bond vibration is recorded parallel to the [001] crystallographic axis and is recognized by a peak in the $3567 \mathrm{~cm}^{-1}$ wavenumber. The experiment is buffered by $\mathrm{Ni}-\mathrm{NiO}$ and the profile is obtained after an experiment at $0.2 \mathrm{GPa}$ confining pressure and a temperature of $1110^{\circ} \mathrm{C}$ with a total hydrothermal exposure for 3 hours [9].

The diffusion profile can be fitted by an erfc-function diffusion profile assuming an infinite source of water outside the sample and considering the finite size of the sample. A strongly anisotropic (Table 1) diffusion profile is obtained where the diffusion of hydrogen into forsterite is described by

Diffusivity $\quad \kappa=\kappa_{p o \text { int }} \exp \left(-\frac{Q_{p o \text { int }}}{R T}\right)$ 
and the fastest diffusion is along the [001] axis, followed by the [010] and finally the [100] axis .

\section{Table 1 Diffusion along $M g$ vacancies in pure forsterite [9]}

\begin{tabular}{|c|c|c|c|}
\hline Crystallographic axes & {$[\mathbf{0 0 1}]$} & {$[\mathbf{0 1 0}]$} & {$[\mathbf{1 0 0}]$} \\
\hline$\kappa_{\text {poinr }}\left[\mathrm{m}^{2} \mathrm{~s}^{-1}\right]$ & $10^{-(3.8 \pm 1.3)}$ & $10^{-(4.6 \pm 1 . .2)}$ & $10^{-(4.3 \pm 1.6)}$ \\
\hline $\mathrm{Q}_{\text {point }}[\mathrm{kJ} / \mathrm{mol}]$ & $210 \pm 33$ & $205 \pm 31$ & $225 \pm 40$ \\
\hline
\end{tabular}

This experiment with pure iron free forsterite confirms an earlier hypothesis of Kohlstedt and Mackwell [10], who claimed that there are indeed two potentially different water related diffusion processes. One process is that of self-diffusion of hydrogen, preferentially along the [100] axis, which is compensated by a flux of polarons (electrons and their associated strain field). Since iron is the source of polarons this first diffusion process is thought to be insignificant in iron free samples [9]. The second process that is observed in both end members of olivine, involves defect sites assumed to be $(\mathrm{Mg}, \mathrm{Fe})$ metal vacancies. This equilibrium diffusion occurs preferentially along the [001] axis. In the olivine where both $\mathrm{Mg}$ and $\mathrm{Fe}$ are present, both the fast meta-stable hydrogen selfdiffusion with strong anisotropy along the [100] axis and the equilibrium diffusion with a fastest axis [001] occurs [10].

Summarizing, we find the most prominent effect of point defects on electrical properties of rocks. They could well explain enigmatic observations in electrical resistivity studies. The notion of metastable charge carriers that are activated in the crust through tectonic stress in the $20-30 \mathrm{~km}$ depth range has been suggested to dominate the electrical conductivity of rocks in the $400-600^{\circ} \mathrm{C}$ temperature range [11]. This region is particarly known in many places worldwide to have a high electrical conductivity [12]. While the experiments discussed here clarify the role of point defects for electrical properties of rocks it is unclear whether the same contention applies to the mechanical properties. It should be emphasized that in the reported experiments, great care has been taken to avoid the presence of linear or planar defects with which there can be considerable interaction. Water mobility can, for instance, be significantly increased along such line defects. 


\section{Line Defects in Olivine}

Early observations on water leakage in fluid inclusions in the crystal quartz showed that water leaks out of these bubbles preferentially along dislocations against thermodynamic gradients in fugacity, chemical potential and pressure [13]. This puzzling phenomenon was later explained by "a molecular water pump" effect attributed to the action of dislocations [14]. According to the molecular dynamics simulations by Heggie the water molecules dissociate in the dislocation cores and $\mathrm{H}^{+}$and $\mathrm{OH}^{-}$become strongly bound to kinks. Heggie goes on to argue that a shear stress, applied to the kinks, pumps the water-bearing species and the undissociated molecules along. The same puzzling observation can be found in olivine. There is a distinct lack of water (Witt-Eickschen pers.com.) in fluid inclusion of olivine nodules that have clearly been exposed to excessively high water conditions in the mantle [15]. However, the mechanism of water leakage is unknown in olivine. The point defect diffusion rates reported above imply that these bubbles should still contain traces of water, because the rate of magmatic entrainment of these nodules to the surface is much faster than the diffusion rate of water.

Although the effect of a molecular water pump is unknown for olivine there is circumstantial evidence through observation of microstructure and microchemistry of naturally deformed olivine grains. The relationship between Fe zoning and kink bands in an iron rich olivine (fayalite) indicates a distinct iron enrichment (Figure 3) along subgrain boundaries consisting of edge dislocation with a [100] slip direction [16]. The authors explain this effect of striped iron zoning through the dislocation enabled dragging of a so-called "Cottrell atmosphere" of solute iron. This effect is not expected to be observed in laboratory experiments, because the experimental rates are too fast.

The exact physical reason for the observations summarized above is still unclear. We can, however, conclude from the affinity of hydrogen proton [100] self-diffusion with $\mathrm{Fe}$, as well as the dislocation pumping process described in quartz and the lack of water in fluid inclusions, that water is a highly mobile species within shear zones. This probably only applies to the regions within the shear zones because outside the shear zones the dislocation density is reduced and the water transfer must rely on the inefficient point defect diffusion process. We argue here that at geological deformation rates the water and Fe-transfer can be facilitated by dislocations and therefore we assume that shear zones can pump their own water. However, this is not possible without limits. We go on to 
a
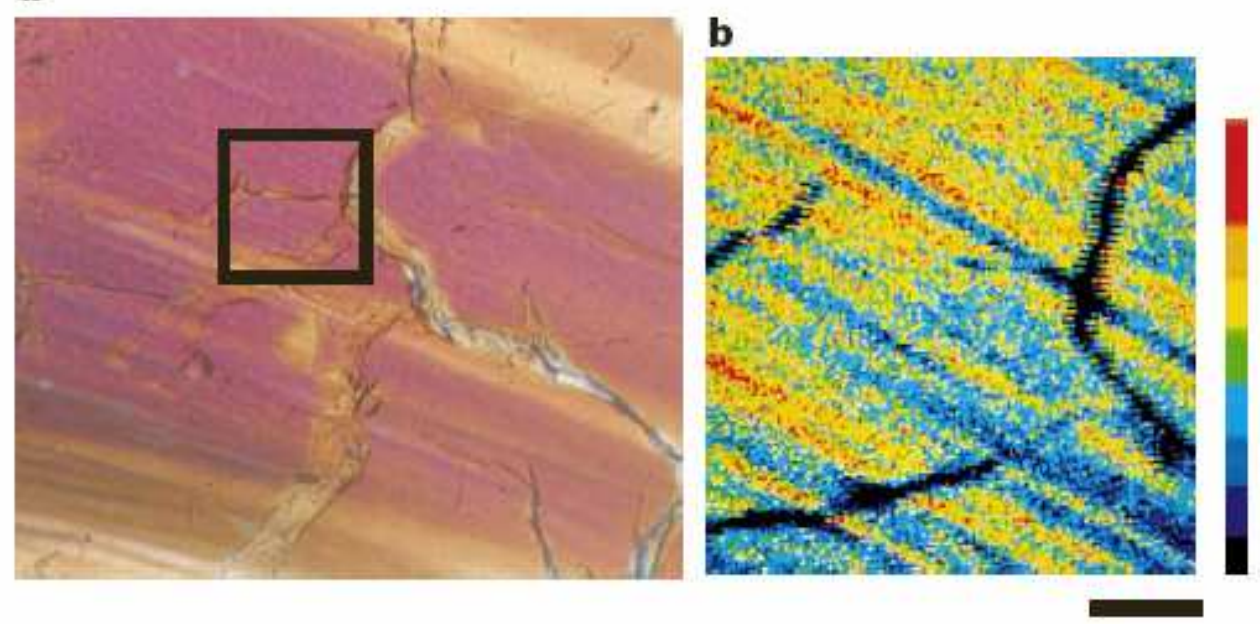

Figure 3 Top: a thin section (in crossed polarized light) of a deformed peridotite derived from the Earth's upper mantle, showing undulose extinction and kink bands (near vertical stripes from the top right to the bottom center). Scale bar, $1 \mathrm{~mm}$. A magnified portion (kink bands now slant diagonally from the top left corner to the bottom) of the thin section is shown in a) cross polarized light and in b) a map of Fe (reddish colors) concentrations within the rectangle of the magnified portion. The scale bar in b) is $30 \mu \mathrm{m}[16]$. 

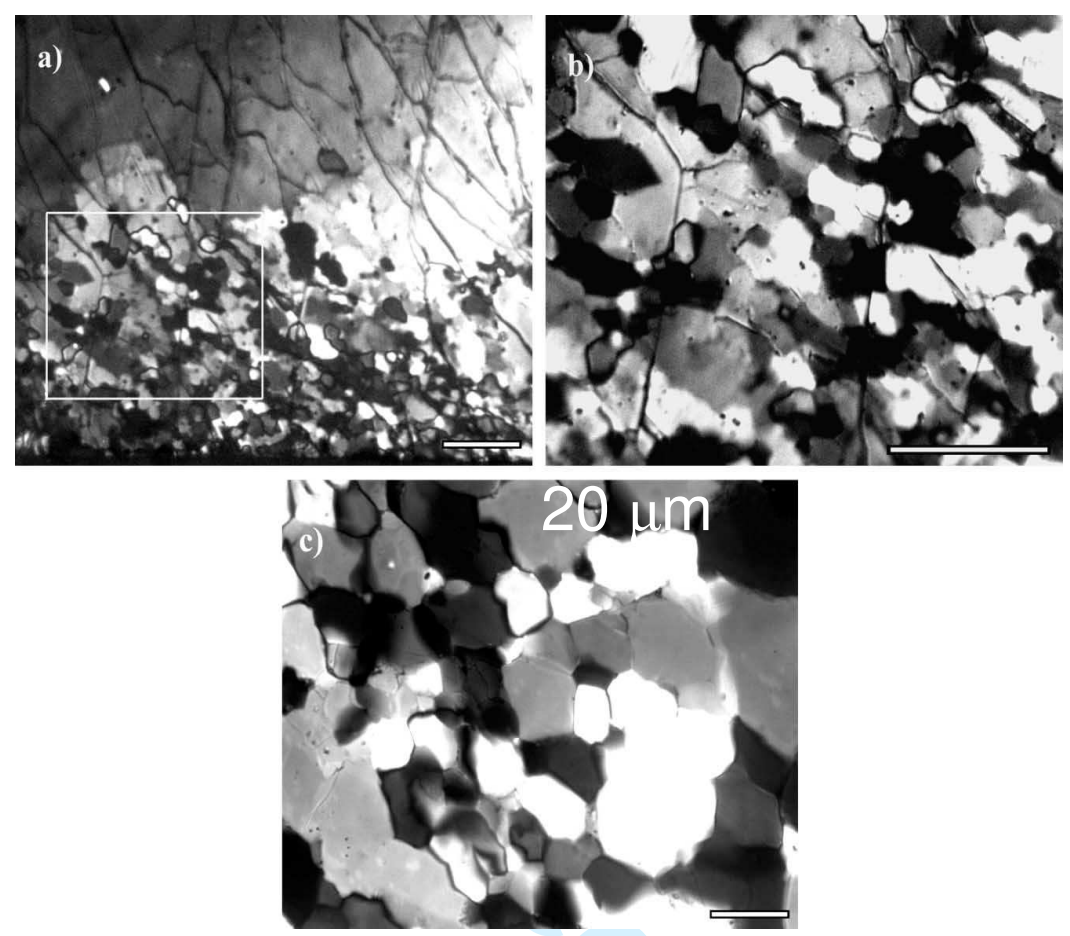

Figure 4 Optical micrographs of a dynamic recrystallization experiment with olivine under controlled water condition. The top a) and b) pictures show' a dry olivine sample with a water content $<200 \mathrm{ppm} \mathrm{H} / \mathrm{Si}$ and the bottom shows a wet sample with a water content of $800 \mathrm{ppm}$ $\mathrm{H} / \mathrm{Si}$. The results of the experiments show that the grain size of the wet sample are larger by a factor of 3 than those of the dry sample. [17]

\section{2-Dimensional Defects in Olivine}

For this we now move up in scale to two-dimensional defects and describe the effect of water on grain size. Experiments on dynamic recrystallization in olivine under controlled water environment have been performed by Jung and Karato [17] and are shown in Figure 4. A distinct non-linear effect of increasing grain size has been observed when the water content exceeds $800 \mathrm{ppm} \mathrm{H/Si}$. Such wet conditions are typical for the asthenosphere but not for the lithosphere [18]. The dislocation pumping action described above may transfer water into the lithosphere within narrow shear zones. The laboratory results of Jung and Karato imply, however, that when the shear zone reaches a water content of around $800 \mathrm{ppm} \mathrm{H} / \mathrm{Si}$ the grain growth effect of dynamically recrystallised grain size prevails and the grain size becomes larger by a factor of 3 to 4 than under water poor conditions. This suggests that under high water content the effect of grain-boundary mobility overcomes the effect of subgrain formation. 
The observed grain boundary migration can have several origins (1) dislocations can be absorbed in the grain boundary, (2) there could be a difference in elastic energy, (3) there is a difference in chemical potential between the grains [19]. The first process is also known as strain-induced boundary migration, and is a fundamental process in primary recrystallization, where the grain with the higher line defect density is consumed by the dislocation free grain. This grain growth process therefore cannibalises the line defect structure and should have an overall damping effect on the enhanced mobility of water. This phenomenon therefore has a self-regulating effect on the water content in natural lithosphere shear zones.

The suggested mechanism transfer of water through 1-D , 2-D and larger scale defects, would in a complete mult-scale framework, lead to a hierarchy of fluid transfer ultimately leading to a superdiffusion process. This could efficiently dehydrate the mantle. We suggest that the observed change in grain size buffers the process and the line defect enhanced mobility of water will hit a threshold when the water content reaches 800 ppm H/Si, which then turns out as a characteristic upper mantle value of water content. Note that these values are still very much below the solubility of water in solid olivine and water does not appear as a free fluid [5].

\section{Mesoscale Summary}

The creep strength presumably depends on the concentration of a water-related crystal defects, which is controlled by the water activity (and thus by the water fugacity $\mathrm{f}_{\mathrm{H} 20}$ ), but at present we do not know the identity of this defect nor the nature of the relationship [20]. In geodynamics we customary use a bulk representation of the material properties, i.e. there is no calculation down to the nano-scale. We assume that we can live with the empirical description of water effect on power law creep in olivine. For power law creep it is convenient to separate out dry and wet creep laws (and their effective stresses and strain rates here defined by the second invariant of the deviatoric stress tensor and its associated strain rate). We use an additive strain rate decomposition and deal with an averaging of effects and ignore the anisotropy [21].

$$
\text { Dry creep } \quad \dot{\varepsilon}^{P(d r y)}=A^{P(d r y)} \sigma^{n} \exp \left(-\frac{E^{P(d r y)}+p V^{P(d r y)}}{R T}\right)
$$


Wet creep

$$
\dot{\varepsilon}^{P(w e t)}=A^{P(\text { wet })} f_{H_{2} O}{ }^{r} \sigma^{n} \exp \left(-\frac{E^{P(w e t)}+p V^{P(w e t)}}{R T}\right)
$$

Combined

$$
\dot{\varepsilon}^{P}=\dot{\varepsilon}^{P(d r y)}+\dot{\varepsilon}^{P(w e t)}
$$

Where $\mathrm{A}^{\mathrm{P}(\mathrm{dry} \text {,wet) }}$ are the power law material constants, $n$ and $r$ are exponents and $E^{P(d r y, w e t)}$ and $V^{P(d r y, w e t)}$ are the dry and wet activation energy and activation volumes, respectively, $R$ is the universal gas constant and $T$ the temperature.

Experiments under controlled water content for investigating low temperature plasticity are still lacking in the geological literature. Low temperature plasticity erroneously was thought to be not important for geological processes. Recent modelling approaches have shown, however, that the Peierls mechanism has a fundamental effect on the thermal-mechanical feedback [22]. The dearth of experimental data hampers our ability to put hard constraints on the effect of water for the planetary behaviour. On the basis of the few publications available with the Vickers hardness test [23, 24] we have introduced a generic empirical description of the effect of water on the Peierls mechanism.

$$
\begin{aligned}
& \text { Dry } \quad \dot{\varepsilon}^{L(d r y)}=\alpha_{d r y} \exp \left(-\frac{H^{L(d r y)}}{R T}\left(1-\frac{\sigma}{\tau_{0(d r y)}}\right)^{2}\right) \\
& \text { Wet } \quad \dot{\varepsilon}^{L(w e t)}=\alpha_{w e t} e \operatorname{xp}\left(-\frac{H^{L(w e t)}}{R T}\left(1-\frac{\sigma}{\tau_{0(w e t)}}\right)^{2}\right)
\end{aligned}
$$

Where the $\alpha_{\text {dry,wet }}$ are reference strain rates and $H^{L[25], L(w e t)}$ are the activation enthalpy, and $\tau_{0(w e t), 0[25]}$ the Peierls stress for wet [24] and dry [23] cases, respectively. We suggest to expand the additive strain rate decomposition (see also Figure 6) to include the wet and dry flow laws of the low temperature plastic mechanism. Likewise, the effect of water on diffusional creep can be added as extra terms [26]. It is hence possible to come up, within one and the same formulation, in a smooth transition from diffusion creep processes deep in the mantle to power law dominated creep deep in the lithosphere to low temperature plastic creep in the shallower lithosphere. Representative material parameters for the later two creep laws are summarized in table 2. 


\section{Table 2 Power law and Peierls creep laws for olivine}

\begin{tabular}{|c|c|c|}
\hline Variable & Value [units] & Explanation \\
\hline$A^{P[25]}$ & $1.26 \mathrm{E}-12\left[\mathrm{~s}^{-1} \mathrm{~Pa}^{-\mathrm{n}}\right]$ & *Prefactor Power Law \\
\hline$A^{P(w e t)}$ & $3.63 \mathrm{E}-18\left[\mathrm{~s}^{-1} \mathrm{~Pa}^{-\mathrm{n}}\right]$ & *Prefactor Power Law \\
\hline$\alpha^{\mathrm{L}(\text { wet })}$ & $5.7 \mathrm{E}+11\left[\mathrm{~s}^{-1}\right]$ & *Prefactor Peierls \\
\hline$\alpha^{\mathrm{L}[25]}$ & 1.2E+12 $\left[\mathrm{s}^{-1}\right]$ & *Prefactor Peierls \\
\hline$E^{P[25]}$ & $510[\mathrm{~kJ} / \mathrm{mol}]$ & $\begin{array}{c}\text { Activation energy (Power } \\
\text { Law) }\end{array}$ \\
\hline$E^{P(w e t)}$ & $470[\mathrm{~kJ} / \mathrm{mol}]$ & $\begin{array}{c}\text { Activation energy (Power } \\
\text { Law) }\end{array}$ \\
\hline$H^{L[25]}$ & $536[\mathrm{~kJ} / \mathrm{mol}]$ & $\begin{array}{c}\text { Activation enthalpy } \\
\text { (Peierls) }\end{array}$ \\
\hline$H^{L(w e t)}$ & $498[\mathrm{~kJ} / \mathrm{mol}]$ & Activation enthalpy $(\mathrm{Pe})$ \\
\hline$V^{P[25]}$ & $1.4 \mathrm{E}-5\left[\mathrm{~m}^{3} / \mathrm{mol}\right]$ & $\begin{array}{l}\text { Activation Volume } \\
\text { (Power Law) }\end{array}$ \\
\hline$V^{P(w e t)}$ & $2.4 \mathrm{E}-5\left[\mathrm{~m}^{3} / \mathrm{mol}\right]$ & $\begin{array}{l}\text { Activation Volume } \\
\text { (Power Law) }\end{array}$ \\
\hline$\tau_{0[25]}$ & $8.5 \mathrm{E}+9[\mathrm{~Pa}]$ & Peierls stress [25] \\
\hline$\tau_{O(w e t)}$ & $9.1 \mathrm{E}+9[\mathrm{~Pa}]$ & Peierls stress (wet) \\
\hline$N$ & & Power Law exponent \\
\hline$r$ & 1.2 & Water content exponent \\
\hline
\end{tabular}

Open issues still remain whether such laboratory laws are good at geological time scale. An example was given that warns us of doing this without careful consideration of the basic physics. The observation of the correlation between micro-chemistry and microdeformation [16] indicates that in laboratory studies, owing to the high rates, we potentially overlook an important chemical effect which is highly relevant for the mobility and the associated weakening effect of water. Multi-scale explorations of timelength scale of diffusion-reaction processes are necessary. Following a simplified basis towards developing a multi-scale formalism we shall step up in scale and look at the planetary scale to identify key problems in geodynamics.

\section{Length scales}

An identification of the basic rulers for a multi-scale formalism is the first step. For an original scientific assessment we neglect the scale transitions for brittle rocks at about $1 \mathrm{~m}^{3}$ size described above. We look at the Earth as if the brittle crust, say the first $10-15 \mathrm{~km}$, is not present. In the discussion we will re-introduce the brittle crust, we only neglect it here for the sake of simplicity. 
The basic rulers for the ductile part of the Earth are:

Point diffusion length scale

$$
l_{o}=M_{p o \text { int }} \sqrt{\kappa_{p o \text { int }} t}
$$

Line defect length scale

$$
l_{1}=M_{\text {line }}\left(\frac{\mu}{\sigma_{\text {ref }}}\right)^{2} b
$$

Grain growth length scale

$$
l_{3}=M_{\text {grain }} \sqrt{\kappa_{\text {grain }} t-g_{0}^{2}}
$$

Thermal diffusion length scale

$$
l_{4}=M_{\text {therm }} \sqrt{\kappa_{\text {therm }} t}
$$

where $M_{\text {point,line,grain,therm }}$ are material parameters and $\kappa \ldots$. the corresponding diffusivities as indicated by their indices, $\mu$ is the elastic shear modulus and $\sigma_{r e f}$ is a reference stress and $b$ the Burgers vector of a line defect [27] and $g_{0}$ the initial grain size. Note that all length scales, except for the line defects (or the material length scale of plasticity), are related to diffusion fronts and therefore grow with time. In a multi-scaling formulation these length scales only play a significant role when they cause a distinct reaction, thus defining a transition length scale. This will be discussed later.

\section{Fractal Plate Tectonics}

So far we have put together a meso-scale framework where the effects from the micro-scale have been averaged into bulk meso-scale properties. We therefore choose to neglect the material length scale of plasticity (nanometer scale) because its macro-scale behaviour is embedded in the bulk averaged properties. In the numerical calculations for larger scales we want to retain, however, some of the physics of the diffusional length scales because we do not know, a priori, whether they play a role at longer time and associated length scale. An observational method for testing the hypothesis of scale invariance is the verification of a fractal distribution of plates, which must be measured in surface area of a unit sphere (the so-called solid angle or steradian) because of the Earth's sphericity. Unfortunately, only 42 plates are identified reliably so that the conclusions 
may not be statistically sound but certainly are significant. The plot of plate area versus cumulative number is shown in Fig.5.

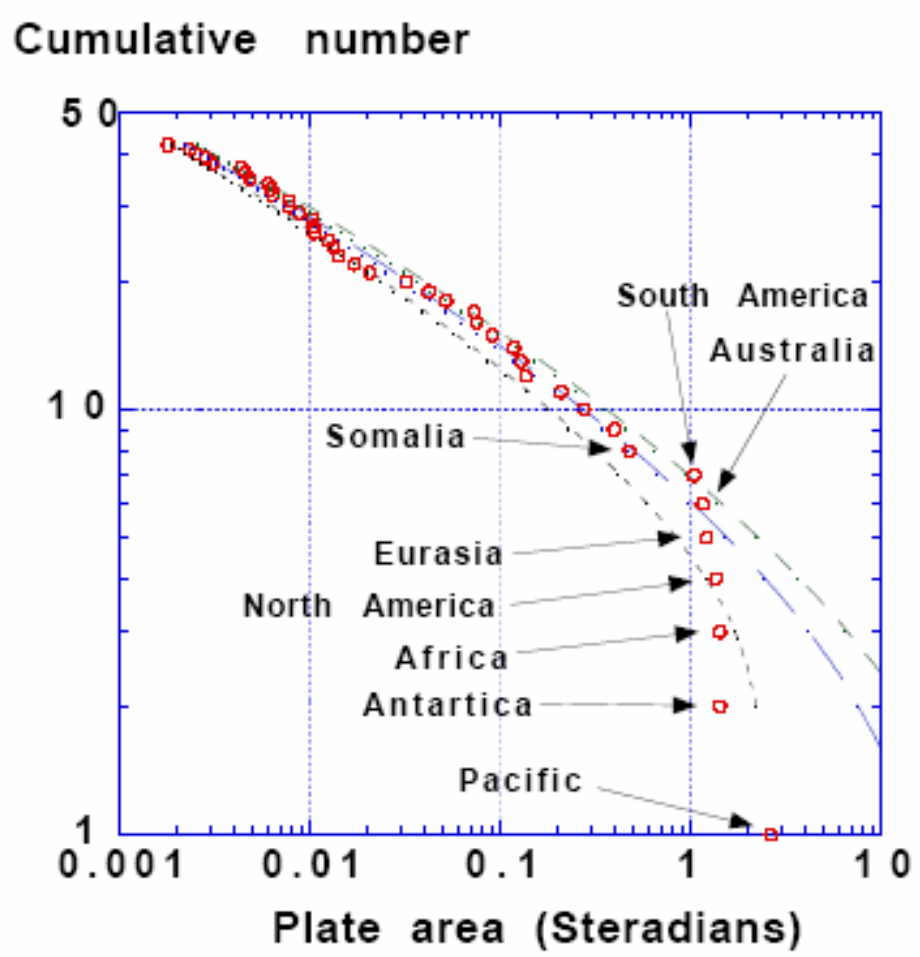

Figure 5 Area of tectonic plates compared to their cumulative number. The best power law fit with upper and lower limits of the $90 \%$ confidence level is shown. The three largest plates, the Pacific, Antarctica and Africa are outside the $90 \%$ confidence level. [28]

A power law fit does a good job. The deviation from the power law distribution of the three largest plates disappears when one modifies the power law to take account of the fact that the sum of the areas over all plates must sum up to $4 \pi$ steradians. Thus, Sornette and Pisarenko [28] conclude that the three largest plates do not play a special role. They belong to the same distribution, and no special mechanism or implication is warranted. The power law fit for the smaller plates is indicative for a hierarchical organization, whereby the same physics applies to all scales from the smallest blocks (O $10 \mathrm{~km})$ to at least the size of the North American plate.

\section{Planetary scale}

The power law distribution for plate tectonics was first noticed by Peter Bird [29], upon refining the plate boundary discretization for his thin shell finite element implementation of the Earth [30]. Bird parameterised all plate boundaries by a simple 
frictional contact approximation and found that the lowest value of friction permissible in his models (0.03) fits the observed stress regime in the Earth best.

An independent line of argument for very weak behaviour on plate boundaries has been put forward long time ago [31]. Using a simple linear instability analysis of the force needed to initiate subduction Dan Mc Kenzie derived that the shear stress on the plate bounding faults cannot be larger than $10 \mathrm{MPa}$. This observation was later known as the subduction initiation paradox since no material in laboratory experiments produced such low strength.

The puzzling observation of Bird that the simple frictional contact approach (Amonton's law) is a poor description of plate boundary faults, indicates that the fragmentation process producing the fractal distribution of plates probably does not reside in the brittle realm. The fragmentation process of plates therefore may be reconciled if the strength is governed by the deep ductile realm. This inference opens, however, the problem of how the inferred low plate boundary strength can be reconciled with the meso-scale flow laws summarized above. A simple extrapolation of the flow laws to a plate tectonic setting gives very strong plate boundaries. In the following we shall explain how the weakening mechanism may operate by non-linear feedback loops and suggest that the criticality of water is the fundamental ingredient in this loop inferring that it is responsible for the fragmentation observed in the self-regulating system Earth. 


\section{Ductile Feedback Loop}

We have proposed a solution to the weak zone paradox for subduction initiation [4] by explicitly calculating the ductile feedback loop (Figure 6).

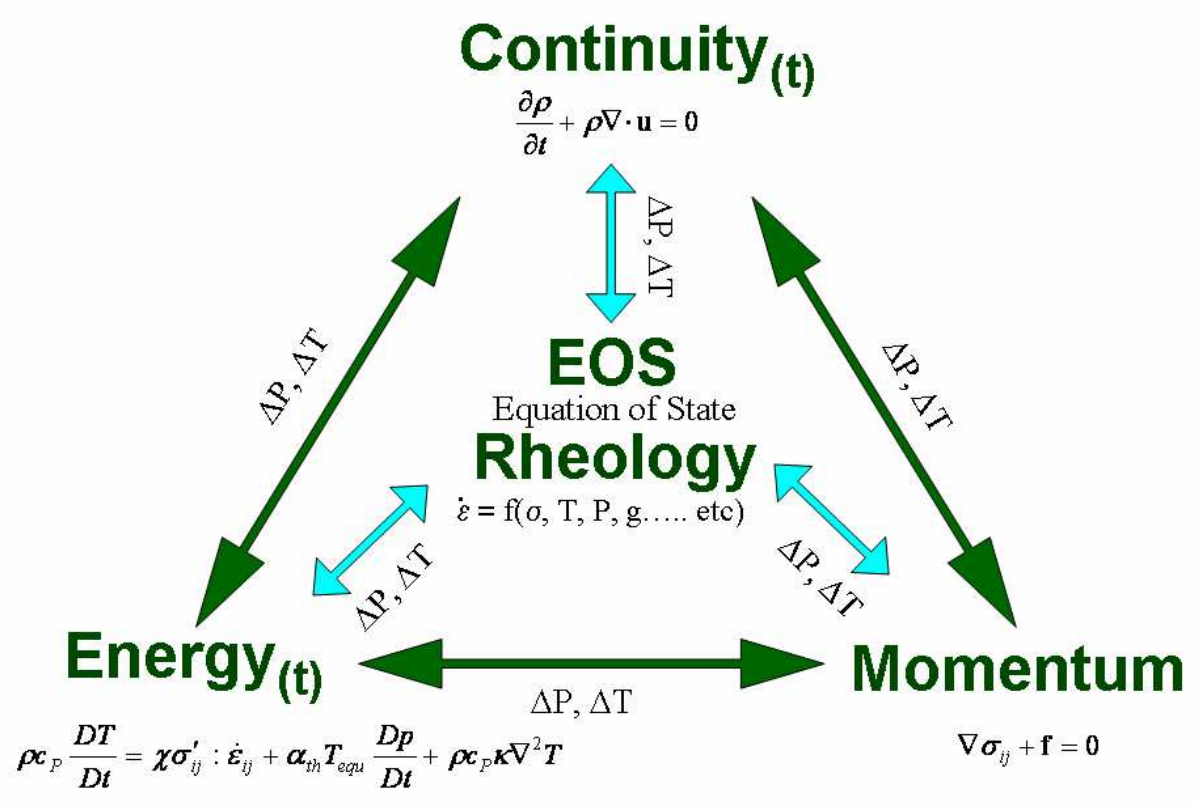

Figure 6 The feedback of the energy-momentum-continuity equations can lead to substantial weakening if a threshold shear heating value is reached. A critical quantity controlling this threshold is the effect of water on power law and Peierls creep. Only a fully coupled algorithm can resolve the feedback.

The key to feedback and weak zone formation lies in the energy equation. In the energy evolution (Figure 6) we have expressed the material time derivative of the total heat evolution DT/Dt (multiplied by density $\rho$ and specific heat $c_{p}$ ) as the sum of the shear heating (scalar product of the deviatoric stress and the strain rate tensors multiplied by a heat conversion efficiency factor $0 \leq \chi \leq 1$ ) the isentropic power (characterized by the thermal expansion $\alpha_{t h}$ ) and the conduction (where $T$ is multiplied by the Laplacian and $\kappa$ is the thermal diffusivity). The energy equation has through the equation of state [32] an immediate impact on the density variation in the continuity equation, here also expressed in the differential form. The divergence of the mass flux away from a reference volume i.e. the product of the nabla operator with the density and velocity $\nabla \cdot \rho \mathbf{u}-$ is equivalent to a density reduction $\_\partial \rho / \partial \mathrm{t}$. The momentum equilibrium for a small reference volume 
closes the feedback loop. It is also given in the differential form expressing the condition that the divergence of the stress tensor $\nabla \cdot \sigma_{i j}$ is in equilibrium with the body forces $\mathbf{f}$.

Consider for simplicity a 1-D system that is under constant shear stress. Let there be an initial perturbation in terms of an arbitrary temperature pulse $\Delta T$. Owing to thermal expansion this goes along with a pressure pulse $\Delta \mathrm{p}$ affecting the momentum equation and the continuity equation through the state dependent rheology and the equation of state [32]. For an explanation of the feedback mechanism we will first only discuss the temperature feedback. If the temperature (or pressure pulse) has a local accelerating effect for creep owing, e.g. to an exponential (Arrhenius) temperature-dependence, there will be locally more mechanical work, and in turn, more shear heating. The thermal-mechanical feeback process is thus self-accelerating and can only be stabilized through conduction of heat away from the local perturbation. If the time constant associated with shear heating is much less than the characteristic thermal diffusion time, then the temperature can increase without limit, i.e. a run-away can occur. This effect has first been suggested by Orowan for the explanation of deep earthquakes [33] and mathematically described by Gruntfest [34] for the simple case of shearing a Boussinesq fluid with Arrhenius temperature dependence. The essence of the ductile thermal feedback relies on this basic principle.

However, upon relaxing the boundary conditions from constant stress to a geodynamic boundary condition the case where shear heating does not outpace the thermal diffusion processes is much more relevant. Under such conditions geodynamic forcing can be controlled by a minimum in the energy dissipation which is obtained by a maximum of thermal-mechanical weakening on an equilibrium shear zone. In such a quasi-static limit the width of the shear zone is proportional to the thermal diffusion length scale [35] obtained for the shear heating time scale (inverse of the strain-rate inside the shear zone). This boils down to the activation of slip lines in the system appearing as heated shear planes. However, the amount of heating is very much smaller for geological shear zones $\left(<20^{\circ} \mathrm{C}\right)$ than for heat lines observed in quasi-adiabatic high speed metal deformation [36]. The main reason why, under similar boundary conditions, rocks are much more susceptible to the thermal weakening mechanism than metals lies in the fact that they have a very low thermal diffusivity $\left(\kappa=10^{-6} \mathrm{~m}^{2} \mathrm{~s}^{-1}\right)$. An approximate estimate of 
the linearized, effective viscosity reduction through feedback for a 1-D shear flow problem with an Arrhenius temperature dependence is

$$
\eta \approx 8 \kappa \rho c_{p} \frac{R T^{2}}{H v^{2}}
$$

$\eta$ is the viscosity on the shear zone after feedback $v$ is the velocity boundary condition , $H$ is the activation enthalpy in the Arrhenius term, $R$ the universal gas constant and $T$ the temperature of the shear flow [37]. The equation is exact for Newtonian viscous flow and a good approximation for power law viscous flow [38]. It is obvious that the thermal-mechanical weakening is maximum for low temperature flows, low diffusivities, high activation enthalpies and high shear velocities.

A similar feedback process also applies to any arbitrary pressure pulse if the rheology is brittle and the yield criterion is based on the state variable pressure. In the classical theories this feedback is simplified into a momentum-continuity equation feedback only through the use of non-associated Mohr-Coulomb plasticity which embeds the fault zone generation into the rheology. In our approach non-associative behaviour arises through the thermal expansion feedback, hence is fully coupled through the energy equation. The simpler classical Mohr-Coulomb approach, which only uses momentumcontinuity feedback, can be used to illustrate the concept of criticality. For such a brittle system it is obvious that under generalized boundary conditions the system may not be pre-stressed close to the Mohr-Coulomb envelope, and an arbitrary pressure pulse may have no effect. If the yield stress is lowered, the system may be closer to criticality and the small pressure pulse may start the instability. For the temperature dependent feedback, described earlier, this is exactly what happens through the addition of water. Water acts simply by lowering the threshold values in the non-linear rheology for creep and thus can act like a toggle switch for activating or suppressing feedback as discussed in more details in the next chapter.

This new, energy-based theory for modelling shear zones in geological and planetary sciences is described elsewhere in full detail [39]. In more general terms the physics of non-linear feedback can lead to the nucleation of a new plate boundary if a 
critical dissipation level is breached inside the plate. Critical material parameters that control the style of instabilities are the activation enthalpy and the ratio of the yield stress over the elastic modulus. Instabilities arise through a rapid conversion of elastically stored energy into shear heating [40]. The water content is the critical parameter for controlling the critical energy level for instability. We have implemented the full equations into the finite element package ABAQUS [35] and looked at the cascading instabilities caused by this feedback process.

\section{Criticality of water}

We have compared a dry and a moderately wet olvine plate by varying the water content systematically from $80 \mathrm{ppm} \mathrm{H} / \mathrm{Si}$ to $200 \mathrm{H} / \mathrm{Si}$. The model setup is shown in Figure 7. The effect of "hydrolytic weakening" has been detected in mesoscale creep experiments, where an addition of water has been noted to increase creep strain rates by an order of magnitude [21]. We use an additive strain rate decomposition, so the fastest creep law dominates the flow process. Let us consider a constant temperature, for example, where the wet power law controls the mechanics of the system. The wet power law states that the strain rate is roughly proportional to the water fugacity multiplied with a non-linear applied stress.

$$
\dot{\varepsilon}^{P(w e t)} \propto f_{H_{2} \mathrm{O}} \sigma^{n}
$$

where the power law coefficient is always larger than 1 for rocks. This implies that the strain rates grows faster for higher applied stress. If the power law exponent $n$ goes to infinity, we recover an ideal yield criterion, i.e. a perfectly plastic body. The water fugacity scales the actual value of this non-linearity (the water fugacity is related to the water content by an Arrhenius relation), and like discussed in the ductile feedback loop dictates whether the system is close or far away from criticality.

Since we are interested in the critical condition for failure, the strength of the 30-45 $\mathrm{km}$ deep layer, the strongest part of the lithosphere, is important. The weaker purely brittle part of the lithosphere (top $10 \mathrm{~km}$ ) has been removed. Details on the model setup and the solution procedure can be found elsewhere [35]. We discuss here the criticality of water for the weakening mechanism that evolves with a cascading of length scales described in the next chapter. 


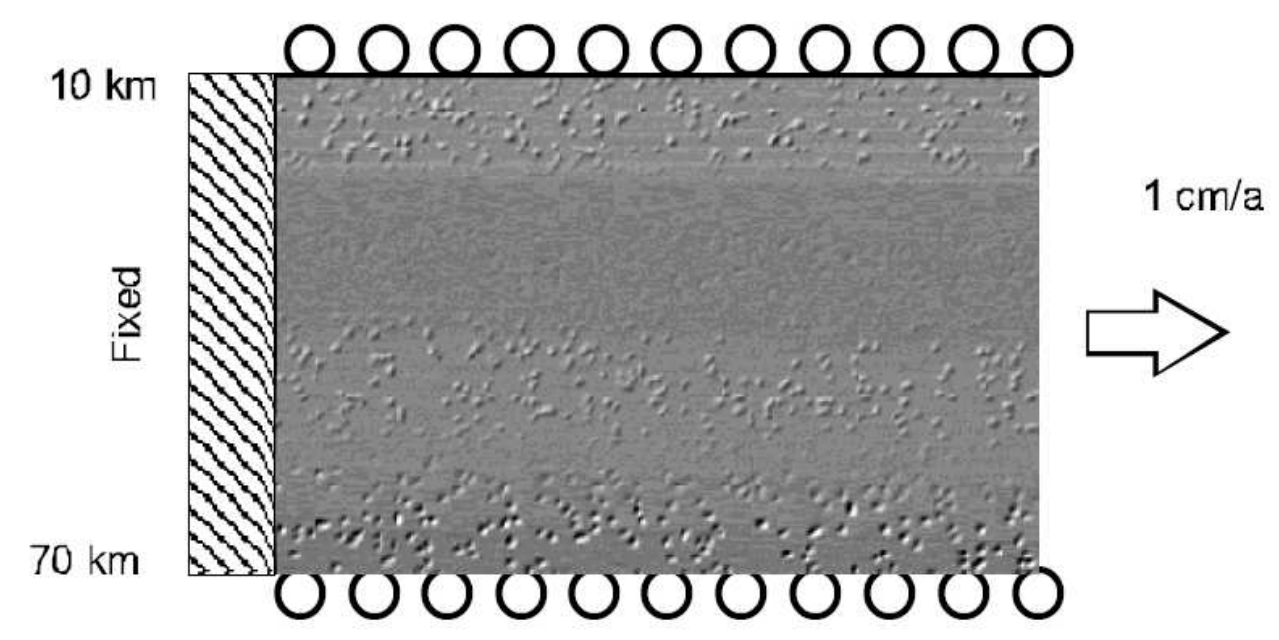

Figure 7 An olivine lithosphere with random thermal perturbations (speckles) in extension $(1 \mathrm{~cm} / \mathrm{a})$. The plate has a thickness of $70 \mathrm{~km}$ and a bottom temperature of $1350 \mathrm{~K}$. The top $10 \mathrm{~km}$ of the lithosphere are neglected. The temperature at the top of the model is $420 \mathrm{~K}$.

Owing to the strong temperature sensitivity of the creep laws the strength increases from the bottom of the model upwards until at about 40-30 km depth. At this depth range the temperature sensitive creep starts to encounter the pressure sensitive regime. For the pressure sensitive regime we use a simplified laboratory approach [41], i.e. a linear increase of the strength with depth, and add this as a fully (co-axial) plastic strain rate in the additive strain rate decomposition. The exact depth of the strong $p$ dependent and $T$-dependent interaction layer, and significant variations of the magnitude of stress, are controlled by the local feedback variables $p$ and $T$.

In the case of a dry olivine lithosphere we find that the strong layer cannot be broken for any reasonable geodynamic forcing. The dynamic strength evolution of a dry and a wet olivine plate are compared in Figure 8. In the modereately wet case the water content has been raised just above the critical value of $186 \mathrm{ppm} \mathrm{H/} \mathrm{Si} \mathrm{and} \mathrm{the} \mathrm{lithosphere}$ can be broken through a cascading instabilities described in the next chapter. Water clearly acts as a critical parameter switching on or off plate scale failure. The same mechanism, with an added external forcing (sediment load) in turn giving rise to flexural bending of the lithosphere, has been used to explain the stronger feedback necessary for the catastrophic onset of subduction initiation [4]. 


\section{Inverse fragmentation}

Sornette and Pisarenko explain the power law relationship of fractal plate tectonics by a process of fragmentation. They point out that the observed power law joint distribution in a granitic massif in Saudia Arabia [42] is capable of explaining the global distribution, if one considers the square root relationship between the plates and their 
boundaries. However, it has also been shown that at the small scale there is a lot of complexity. Different geometrical power laws and anisotropic textures appear to hold in distinctly limited ranges, which in turn can be related to the main rheological interfaces in the Arabian crust [42]. This is part of the reason why we did not discuss the brittle regime. The proximity of the plate size distribution to joint distribution in granites points to a ductile process, which is currently under revision as a new paradigm for granite generation [43-46].

In contribution to the new paradigm of shear-assisted melt segregation we have extended our calculations to include the additional feedback of ductile fracture through the shear interaction of melt inclusions. In these preliminary calculations we confirm a two-stage feedback already described earlier [47]. We first see a thermal Mode 2 crack like phenomenon that propagates through the granite cascading from small to large length scales, thus preparing the future pathways for granite genesis and in a second cascade the melt pockets coalesce along the thermal Mode 2 crack trajectories.

It is premature to draw from our present results predictions for the size distribution of plates since we look at a vertical cross section through the lithosphere and do not solve the interaction of the plates, nor their relation to mantle convection, or their evolution over time. All of our models including the plate scale processes discussed above have, however, shown an inverse fragmentation process in the ductile realm from small to long length scales achieving minimum dissipation for long time scales. The simple conclusion is that for the longest time scale the largest fault is the most stable one. In a plate tectonic process there exist three opposite normal fragmentation trends: one in which oceanic plates are constantly consumed; the second the continent dispersal phenomenon in the Wilson cycle; and the third, the supercontinent cycle, where supercontinents are dispersed.

\section{Summary and Discussion}

In the introduction we have presented the postulate that the presence of water is crucial for the emergence of plate tectonics out of planetary convection. We have also shown that shear zones that tap the asthenosphere possibly can pump water upwards through the propagation of line defects. This water pumping effect may not be visible at laboratory deformation rates but can be sufficient at geological rates. This implies that 
shear zones can carry their own water for their propagation. This process is probably limited by consumption of dislocation in two-dimensional defects, which can switch off the water pumps for a water content $>800 \mathrm{ppm} \mathrm{H} / \mathrm{Si}$. The asthenosphere is presumably much richer in water $(880 \mathrm{ppm} \mathrm{H/Si})$ compared to the lithosphere at the mid-ocean ridge (80 ppm H/Si) [18]. We have demonstrated further, assuming a scale invariance from meso- to the macro-scale, that the criticality of water can lead to plate scale failure. An efficient way of lithosphere failure may therefore be initiated from below the plate. This can be caused by a surface load through flexure of the plate from above, or through a convective instability at the bottom of the lithosphere. We have finally discussed the notion of scale invariance past the meso-scale and reviewed a fractal plate tectonic interpretation.

There are a couple of hot research areas, which need to be addressed within a multiscale framework. We come to the conclusion that the brittle part of plates can possibly be neglected when dealing with processes at the time scale of fractal plate tectonics $(\mathrm{O} 0.5$ Ga-cycle). However, this notion is not true when dealing with processes around $10 \mathrm{~km}$ scale. What we see at surface is just the brittle crust. This scale is thus of crucial importance for the engineer, geologists and seismologist and there is a shortage of multiscaling approaches. For processes in the ductile realm, likewise, different scales emerge depending on the time scale of observation and the different diffusivities encountered. We cast this into a tentative diffusion-reaction chart, where we pick up the main points of the meso-scale discussion. This diffusion-reaction chart essentially offers a means for simplification of the problem. For different time and spatial scales different weakening mechanisms are important.

The mechanism of grain growth in olivine is extremely fast, under wet experimental conditions [48]. The grain size sensitive creep mechanism can cause a reaction (weakening) when the grain size is reduced. This is effectively limited by the physics of grain growth. We use experimental data of grain growth reported above [48] and obtain a lower bound for the grain growth time. Accordingly, at relatively low temperatures (say $950 \mathrm{~K}$ ) a $50 \mu \mathrm{m}$ grain grows with the grain growth equation for olivine (Figure 9) to almost millimetre size within the period of thousand years. This short time scale highlights the grain size sensitive creep mechanism as a strong candidate for investigation of the recurrence time of large earthquakes, which is of the order of a thousand years. For a multi-phase material the grain growth is slower however, 
diffusional flow is currently not considered to be a strong candidate for creation of plate tectonic boundaries.

At the time scale beyond 1000 years, we are interested in understanding the formation of new plate boundaries. Wholesale lithosphere failure can also be very fast and happen on the time scale of 100 kyrs [47]. For calculating this time scale only the shear heating phenomenon has been used. We can see from the diffusion-reaction chart that these results should be revisited by inclusion of the grain size dependent mechanism, because of the close time-space proximity of shear-heating and grain size mechanism. After a time scale of 100 kyrs the thermal diffusion front that has been created by shear heating inside the shear zone, has travelled almost $1 \mathrm{~km}$ perpendicular to the shear zone and thereby is about to leave the realm of observed shear zone width (equation in Figure 9). In the feedback calculations the shear heating mechanism for faulting in fact stabilizes on a characteristic thermal diffusion length, where shear heating and thermal diffusion are in equilibrium.

For the yet larger time and space scale of the entire Earth we would want a diffusion front that does not leave the plate bounding shear zones for the lifetime of the Earth. When taking the point defect diffusion for the fastest axis [001] in synthetic forsterite (Table 1) at $950 \mathrm{~K}$, water will not even have migrated more than $10 \mathrm{~m}$ perpendicular to the shear zone on the time scale of the Earth. When taking the faster value of meta-stable hydrogen transfer in olivine that contains Fe [10], the diffusion front still has only reached only $400 \mathrm{~m}$ on either side of the shear zone. This example illustrates that wet shear zones, once they have severed through the lithosphere through a hierarchy of defects, can remain wet for the time scale of the Earth. They thereby control the stiffness of the outer layer of a planet and fundamentally affect planetary behaviour. It is, however, crucially important to complement these initial analyses by "ab initio" based calculation techniques.

In summary we conclude that, if we were to look for processes that can weaken the plates in the time interval $<1000$ years the grain size dependent creep process is an important candidate for investigation, because it operates on the fast time scale of grain growth [48]. For the time scale of hundred thousand years or larger the thermal diffusion process within shear zones is important. The water weakening process will act on the time scale of the Earth since the diffusivity of point defect is so slow that water remains effectively contained within the shear zones. 


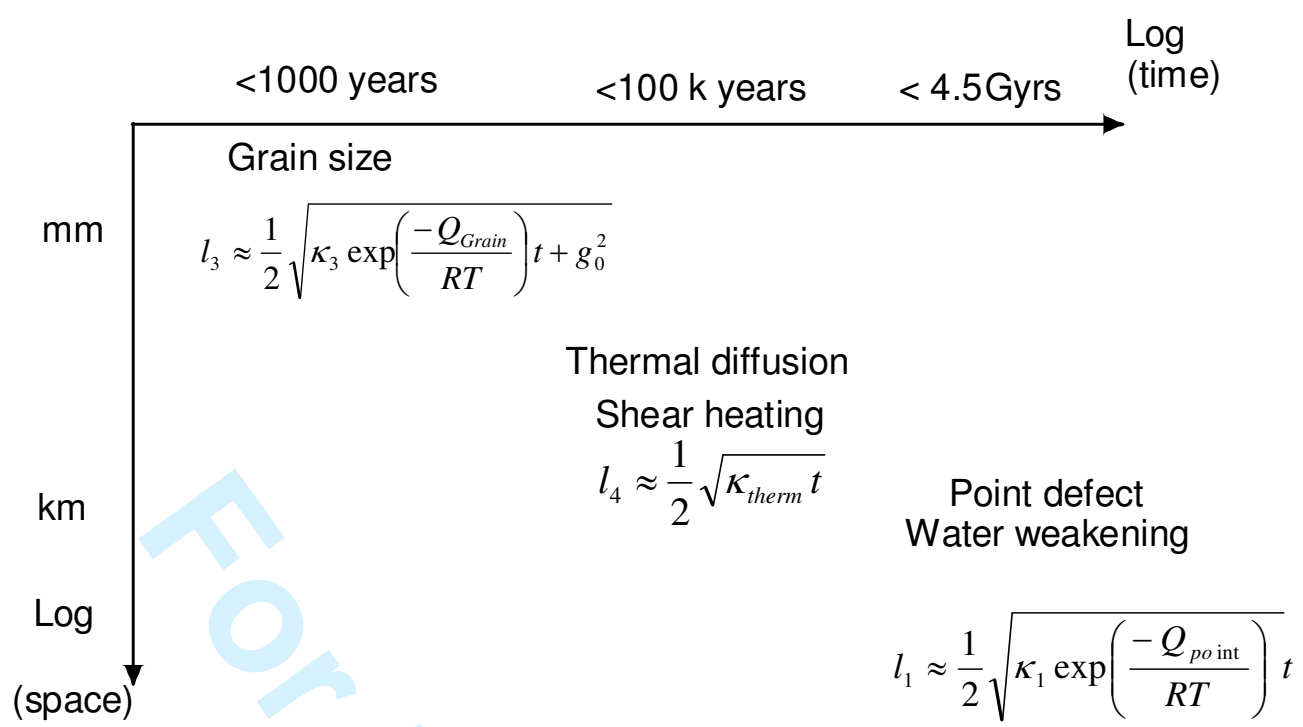

Figure 9 Diffusion -reaction chart showing where additional scaling length may come into place in a multiscale ductile formulation. The material parameters for point defect diffusion are listed in table 1, the thermal diffusivity $\kappa_{\text {therm }}=1 \times 10^{-6} \mathrm{~m}^{2} \mathrm{~s}^{-1}$, the grain growth for the wet case is characterized by $\kappa_{3}=1 \times 10^{-8} \mathrm{~m}^{2} \mathrm{~s}^{-1}$ multiplied with the Arrhenius term whereby $Q_{\text {grain }}=160 \mathrm{~kJ} / \mathrm{mol}$ and $\mathrm{g}_{0}$ is the initial grain size [48].

\section{Acknowledgments}

$\underline{\text { We would like to acknowledge financial support from a wide range of international }}$ research organizations, notably: the Australian Predictive Mineral Discovery CRC (pmd*CRC), CSIRO Exploration and Mining, the Australian Computational Earth System Simulator (ACcESS) MNRF, the Swiss National Fund, the CSEDI, Math-GEO and ITR grants from the National Science Foundation as well as the Johannes GutenbergUniversität Mainz. 


\section{References:}

1. Kaula, W.M., The Tectonics of Venus. Philosophical Transactions of the Royal Society of London Series a-Mathematical Physical and Engineering Sciences, 1994. 349(1690): p. 345-355.

2. Lenardic, A., W.M. Kaula, and D.L. Bindschadler, Some Effects of a Dry Crustal Flow Law on Numerical Simulations of Coupled Crustal Deformation and Mantle Convection on Venus. Journal of Geophysical Research-Planets, 1995. 100(E8): p. 16949-16957.

3. Moresi, L. and V. Solomatov, Why Does Earth Have Plate Tectonics? Geological Journal International, 1998. 133: p. 669.

4. Regenauer-Lieb, K., D. Yuen, and J. Branlund, The Initation of Subduction: Criticality by Addition of water? Science, 2001. 294: p. 578-580.

5. Regenauer-Lieb, K. and T. Kohl, Water solubility and diffusivity in olivine: Its role for planetary tectonics. Mineralogical Magazine, 2003. 67: p. 697-715.

6. $\quad$ Pinto da Cunha, A., Scale effect in Rock Masses 93. Proceedings of the 2 nd international workshop on scale effects in rock masses (Lisbon, Portugal). 1993, Rotterdam: A.A. Balkema.

7. Sornette, D., Earthquakes: from chemical alteration to mechanical rupture. Physics Reports-Review Section Of Physics Letters, 1999. 313(5): p. 238-291.

8. Deer, W., R. Howie, and J. Zussman, An Introduction to the Rock-Forming Minerals. 1992, Harlow: Longman. 712.

9. Demouchy, S. and S. Mackwell, Water diffusion in synthetic iron-free forsterite. Physics and Chemistry of Minerals, 2003. 30(8): p. 486-494.

10. Kohlstedt, D.L. and S.J. Mackwell, Diffusion of hydrogen and intrinsic point defects in olivine. Zeitschrift Fur Physikalische Chemie-International Journal of Research in Physical Chemistry \& Chemical Physics, 1998. 207: p. 147-162.

11. Freund, F., Time-resolved study of charge generation and propagation in igneous rocks. Journal Of Geophysical Research-Solid Earth, 2000. 105(B5): p. 1100111019.

12. Freund, F., On the electrical conductivity structure of the stable continental crust. Journal Of Geodynamics, 2003. 35(3): p. 353-388.

13. Bakker, R.J. and J.B.H. Jansen, Preferential water leakage from fluid inclusions by means of mobile dislocations. Nature, 1990. 345: p. 58-60.

14. Heggie, M., A molecular water pump in quartz dislocations. Nature, 1992. 355: p. 337-339.

15. Witt-Eickschen, G., H.A. Seck, and C. Reys, Multiple enrichment processes and their relationships in the subcrustal lithosphere beneath the Eifel (Germany). Journal of Petrology, 1993. 34(1): p. 1-22.

16. Ando, J., et al., Striped iron zoning of olivine induced by dislocation creep in deformed peridotites. Nature, 2001. 414(6866): p. 893-895.

17. Jung, H. and S.I. Karato, Effects of water on dynamically recrystallized grain-size of olivine. Journal of Structural Geology, 2001. 23(9): p. 1337-1344.

18. Hirth, G. and D.L. Kohlstedt, Water in the oceanic upper mantle: implications for rheology, melt extraction and the evolution of the lithosphere. Earth and Planetary Science Letters, 1996. 144: p. 93-108. 
19. Poirier, J.-P., Creep of Crystals: High temperature deformation processes in metals, ceramics and minerals. 1985, Cambridge: Cambridge University Press.

20. Post, A. and J. Tullis, The rate of water penetration in experimentally deformed quartzite, implications for hydrolytic weakening. Tectonophysics, 1998. 295(1-2): p. 117-137.

21. Karato, S.I. and H.Y. Jung, Effect of pressure on high-temperature dislocation creep in olivine. Philosophical Magazine A, 2003. 83(3): p. 401-414.

22. Kameyama, C., D.A. Yuen, and S. Karato, Thermal-mechanical effects of low temperature plasticity (the Peierls mechanism) on the deformation of a viscoelastic shear zone. Earth and Planetary Science Letters, 1999. 168: p. 159162.

23. Goetze, C. and B. Evans, Stress and temperature in the bending lithosphere as constrained by experimental rock mechanics. Geophysical Journal of the Royal Astronomical Society, 1979. 59: p. 463-478.

24. Evans, B. and C. Goetze, The temperature variation of the hardness of olivine and its implications for the polycrystalline yield stress. Journal of Geophysical Research, 1979. 84: p. 5505-5524.

25. San'kov, V., et al., Geometry and rate of faulting in the North Baikal Rift, Siberia. Tectonics, 2000. 19(4): p. 707-722.

26. Mei, S. and D.L. Kohlstedt, Influence of water on plastic deformation of olivine aggregates: 1.Diffusion creep regime. Journal of Geophysical Research, 2000. 105(B9): p. 21457-21469.

27. Gao, H., Y. Huang, and W.D. Nix, Modeling plasticity at the micrometer scale. Naturwissenschaften, 1999. 86(11): p. 507-515.

28. Sornette, D. and V. Pisarenko, Fractal plate tectonics. Geophysical Research Letters, 2003. 30(3).

29. Bird, P., An updated digital model of plate boundaries. Geochemistry Geophysics Geosystems, 2003. 4.

30. Bird, P., Testing hypotheses on plate-driving mechanisms with global lithosphere models including topography, thermal structure, and faults. Journal of Geophysical Research-Solid Earth, 1998. 103(B5): p. 10115-10129.

31. McKenzie, D.P., The initiation of trenches: A finite amplitude instability, in Island Arcs Deep Sea Trenches and Back-Arc Basins, M. Talwani and W.C. Pitman, Editors. 1977, Maurice Ewing Ser. Vol. 1. p. 57-61.

32. eos, 1. The equation of state.

33. Orowan, E., Mechanism of seismic faulting, in Rock Deformation (A Symposium), D. Griggs and J. Handin, Editors. 1960: Washington. p. 323-346.

34. Gruntfest, I.J., Thermal Feedback in Liquid Flow - Plane Shear at Constant Stress. Transactions of the Society of Rheology, 1963. 7: p. 195-207.

35. Regenauer-Lieb, K. and D.A. Yuen, Positive feedback of interacting ductile faults from coupling of equation of state, rheology and thermal-mechanics. Physics of Earth and Planetary Interiors, 2004. 142(1-2): p. 113-135.

36. Johnson, W., G.L. Baraya, and R.A.C. Slater, On heat lines or lines of thermal discontinuity. International Journal of Mechanical Sciences, 1964. 6: p. 409-507.

37. Yuen, D.A., et al., Shear Deformation Zones Along Major Transform Faults and Subducting Slabs. Geophysical Journal of the Royal Astronomical Society, 1978. 54(1): p. 93-119.

38. Fleitout, L. and C. Froidevaux, Thermal and Mechanical Evolution of Shear Zones. Journal of Structural Geology, 1980. 2(1-2): p. 159-164. 
39. Regenauer-Lieb, K. and D.A. Yuen, Modeling Shear Zones in Geological and Planetary Sciences: Solid- and Fluid-Thermal-Mechanical Approaches. Earth Science Reviews, 2003. 63: p. 295-349.

40. Regenauer-Lieb, K. and D. Yuen, Rapid conversion of elastic energy into shear heating during incipient necking of the lithosphere. Geophysical Research Letters, 1998. 25(14): p. 2737-2740.

41. Kohlstedt, D.L., B. Evans, and S.J. Mackwell, Strength of the lithosphere: Constraints imposed by laboratory measurements. Journal of Geophysical Research, 1995. 100(B9): p. 17587-17602.

42. Ouillon, G., C. Castaing, and D. Sornette, Hierarchical geometry of faulting. Journal of Geophysical Research-Solid Earth, 1996. 101(B3): p. 5477-5487.

43. Rabinowicz, M. and J.L. Vigneresse, Melt segregation under compaction and shear channeling: Application to granitic magma segregation in a continental crust. Journal of Geophysical Research-Solid Earth, 2004. 109(B4).

44. Weinberg, R.F., A. Sial, and G. Mariano, Close spatial relationship between plutons and shear zones. Geology, 2004. 32(5): p. 377-380.

45. Vigneresse, J.L., The implications of a new paradigm for granite generation and ore. Geochimica Et Cosmochimica Acta, 2003. 67(18): p. A514-A514.

46. Leitch, A.M. and R.F. Weinberg, Modelling granite migration by mesoscale pervasive flow. Earth and Planetary Science Letters, 2002. 200(1-2): p. 131-146.

47. Regenauer-Lieb, K. and D.A. Yuen, Fast mechanisms for the formation of new plate boundaries. Tectonophysics, 2000. 322: p. 53-67.

48. Karato, S.I., Grain growth kinetics in olivine aggregates. Tectonophysics, 1989. 168: p. 253-257. 